\title{
Nephrology Education in the Electronic Era - A Case Based Review
}

\author{
Kenar D. Jhaveri ${ }^{* 1,2}$, Deepa Malieckal ${ }^{1}$, Ezra Israel ${ }^{2}$ and Tushar Vachharajani ${ }^{3}$ \\ ${ }^{I}$ Department of Internal Medicine and Division of Kidney Diseases and Hypertension, North Shore LIJ Health System, \\ Hofstra North Shore LIJ School of Medicine, 100 Community Drive, Great Neck, NY 11021, USA \\ ${ }^{2}$ Nephrology Division, W. G. (Bill) Hefner ${ }^{3}$ VA Medical Center - Salisbury, NC, USA
}

\begin{abstract}
As the field nephrology is rapidly advancing, technological changes are changing the face of learning. Understanding how the current generation of "digital natives" learn and understand topics is vastly important. The current students and residents were born when computers and electronic gadgets were considered a part and parcel of their learning structures. The primary focus of this review is on the change in learning and teaching modalities in this digital age and how we foresee the future of nephrology education in a case based format.
\end{abstract}

Keywords: Nephrology education, e learning, blogs, twitter, Google, web based learning, internet.

\section{INTRODUCTION}

Today's learners represent the first generations to grow up with new technology since they were born. The current era learners have spent their entire lives surrounded by computers, videogames, digital music players, video cameras and newer versions of cell phones. A terminology penned by Mark Prensky is used to describe the current learners"digital natives"[1]. The teachers who are trying to speak this language of the digital natives are called the "digital immigrants". Today's teachers have to learn to communicate in the language and style of their students and focus on the content load that the current students can handle. Strauss and Howe describe this generation as the millennials [2]. They describe certain traits of this generation that might be useful when we develop teaching techniques. The millennials are indulging, easily distracted but can multi task. They are sheltered and expect extra help and guidance from mentors. Optimism and team work are part of their core values. While Generation $\mathrm{X}$ was motivated by power, this generation is motivated by achievement and affiliation. They expect communication face to face or via email, phone or texting. They prefer writing and reading in concise forms such as a text message [2]. Learners in nephrology are no different. The current e- learning technologies can be of aid to such learners. This review will highlight using cases to discuss how the future of learning might take place in nephrology. In certain centers, these techniques might have already been employed.

\section{CASE 1}

A 22 year old medical student is asked to do a presentation on Ig A Nephropathy. She gives you a concise 30 minute presentation. When you ask her where you found most of your information, she says, "I just "googled" it"! When asked - "Did you use Pubmed?"

*Address correspondence to this author at the 100 Community Drive, Second Floor. Division of Kidney Diseases and Hypertension, Hofstra North Shore LIJ School of Medicine, Great Neck, NY 11021, USA;

Tel: 1516465 8207; Fax: 1516465 8202; E-mail: kdj200@gmail.com
She replies: No. Google was able to provide me most of the information. Overall, you were still impressed with the presentation.

The field of nephrology is constantly changing and it is essential to have the most up to date information for good practice. Advancements in technology have improved the way that people function in everyday life including the way that people learn and share knowledge. With the introduction of the internet came many changes in the way people learn nephrology. Information sharing through the internet has opened a new window to "e-learning" as a way that people can advance their knowledge $[3,4]$. This applies to all students and healthcare professionals in training and currently practicing. People generally have different preferences in how they learn or study [5].

In the current day and age electronics have empowered people with information at their fingertips. Whether on a computer, smart phone, PDA, ipad, eBook people can access educational information without having to actively search for a book or journal. A combination of visual, reading, and auditory learning can be accessed easily through internet blogs, social media, you tube, chat forums, modules, shared power points and video streaming [5]. Textbooks can be found online without people having to lug around heavy books. All of these information retrieval avenues contribute to answer any questions people may have on the spot.

The above case illustrates the example of a different search engine that current students, residents and fellows might be using compared to what the teachers are using. The concept of Google ${ }^{\mathrm{TM}}$ as a successful medical search engine is not novel [6,7].

Increasingly, medical students, residents, and attending physicians have been using the Internet as a tool for diagnosing and treating disease. There have been several recent reports of patients and physicians-in-training "Googling" the answer to a medical question that had experts stumped. The use of technology employs an algorithmic, rather than a heuristic, approach to medical problem-solving and at speeds much greater than human 
capacity, thereby making brute force efforts possible. Various technologies have been experimented with in medicine for years. Past efforts have included computer programs specifically designed to make medical decisions and diagnose conditions for clinicians. Decision technology does not merely facilitate or augment decision-making, rather it reorganizes decision-making practices. A recent abstract presented at American Society of Nephrology(ASN) compared residents who "googled" key words of common and rare nephrology related diagnosis to experienced attendings, junior attendings and fellows in training who did not use Google TM. Overall, the "Googlers" correctly diagnosed renal diseases less often than the nephrology attendings $(72.2 \%$ vs $84.7 \%, \mathrm{p}<.001)$, but with the same frequency as the nephrology fellows $(72.2 \%$ vs $71.5 \%$, $\mathrm{p}=.795$ ) [8]. As these search engines are becoming diagnostic tools for many physicians and patients, we must not forget the art of medicine. Although these technologies might help in getting us the information, using primary data to treat our patients is more important. While we embrace these newer search engines and different modes of thinking, we should not forget the logical steps in medicine about differential diagnosis and conceptual thinking.

\section{CASE 2}

A medical resident is asked to pick a journal club article for his nephrology rotation. The attending asks him, how did you choose the article? He replies: "I was on facebook and "liked" and became friends with " $A S N$ ". Many followers on ASNfacebook page were having a heated discussion on a new article on the effect of days on which dialysis patients have the greatest mortality. Interestingly, this article was published in the New England Journal of Medicine.

How is Facebook useful in medical education? This case is an example of how potential students might be using such websites for their use in education. Facebook serves as an informal platform for students and residents to obtain and disseminate information. This resident has become "friends" on Facebook with many medical organizations and perhaps many medical journals. The resident regularly visits his/her Facebook page. Constant updates of new articles with and without comments can be found daily on their page. Other social media websites such as Twitter and Google plus can be used for similar purposes. Such tools end up serving as resources for journal articles and medical news updates at your fingertips. A recent publication describes a study where medical students used Facebook as a training channel for professional habits [9]. This is one example of how such tools can help residents and fellows in training. Many nonprofit nephrology groups like the ASN and the National Kidney Foundation (NKF) can easily be found on Facebook. If you "friend" them (that act of adding the group as a friend on facebook) you will be provided with a newsfeed that has their most recent posts keeping you up to date with the most recent nephrology topics, conferences, and meetings. People also have the chance to "like" a posted comment. These applications inspire people to be more outspoken about their interests.

\section{CASE 3}

A 29 year old nephrology fellow has shared his journal club choice of manuscript to the fellowship Twitter account. After one week of reading time, discussion is started on Twitter about the article and continues for one week. Following that, the fellow summarizes the findings for all on the division blog. In addition, the journal where the article was published also allows for a virtual journal club and discussion is also posted there for comments directly from the author.

The easy ability to access information quickly on the internet has influenced medicine in the classroom as well as in the hospital setting. Healthcare providers use online medical information for self-directed learning and patient care. Website blogs and learning resources are easily found online with the click of a mousethrough search engines. Medical journals that were usually retrieved via the library and mail are now easily accessed online. As a member of internet journals, you can be provided with daily email alerts of the newest findings in studies and recommendations in practice.

One of these sources is blogs. Blogs are personal journals published on the World Wide Web consisting of discrete entries or "posts." They are usually the work of single individuals or small groups, and often are themed on a single subject. Many different kidney themed blogs are on the internet and provide avenues for medical students, residents, fellows and attending to interact with people of the same interest throughout the world. For example, if a topic is posted, anyone can comment thereby sharing their take on a topic, add to the knowledge base of it, or challenge the idea. Any questions asked can be answered by simply presenting a case online and then having people from anywhere give their input, collectively improving the thought process. A summary of nephrology based blogs can be found in recent reviews of the literature [3]. Individual physician based blogs have paved the way for journal based blogs. Information in a journal based blog is less likely to be incorrect and more likely to have gone through editing and review before posting. Many reputable journals have begun creating blogs although the content varies widely. Many journal websites also support sharing of information by allowing readers to "like" articles with Facebook, "tweet" about them with Twitter or email them to colleagues. Few leading medical publications have taken further steps toallow readers to comment directly after the article in the journal's main website and the blogs. A recent study looked at all journal blogs in science and medicine with impact factor $>4.0$ and found that while nephrology journals had $100 \%$ social media sharing features of their articles, only $14 \%$ had blogs and none had direct commenting features on their website [10].

The above case describes a virtual journal club that is possible and currently being used in many centers. This allows for a larger discussion. Twitter journal clubs [11] have gained some attention in medical education. Journal based websites and blogs might be other means of enhancing communication and discussion directly with the authors and providing a more meaningful journal club. In nephrology, the American Journal of Kidney Disease launched their official blog called eAJKD [12]. This journal based blog has multiple teaching tools and author interviews for discussion. This is the first nephrology journal related blog to our knowledge. Clinical Journal of the American Society of 
Nephrology has a virtual journal club [13] that has used a similar concept as the twitter journal club to enhance communication. Such tools can be used within fellowships to enhance the journal club experience as well. More journals and fellowships around the world should start embracing such technologies for use in medical education.

In a study done by Bahner et al. at Ohio State University, a majority of people found daily "tweets" that were posted on Twitter and Facebook informative allowing them to learn easily via means as simple as their mobile phone [14]. In 2010, a study was done at the Penn State College of Medicine involving fourth year medical students evaluating their use and integration of new social media tools into the curricula of two graduate-level medical humanities electives offered to them [15]. Social media tools (Twitter, YouTube, Flickr, blogging and Skype) were used to promote student learning. At the completion of the course students gave high ratings to both courses, and expressed that the integration of social media into coursework augmented learning and collaboration. This experiment showed that integrating social media tools into class activities appeared to offer many benefits over traditional classroom methods, including realtime communication outside of the classroom, connecting with medical experts, collaborative opportunities and enhanced creativity. A more recent study analyzed the use of twitter in the ASN 2011 meeting [16]. The twitter way of sharing knowledge is showing significant area of promise to share kidney-specific educational information with the public.

\section{CASE 4:}

A 30 year old nephrology fellow in a third world country is able to access expert nephrology talks on YouTube. Besides her regular training, she is able to access excellent peer reviewed evidence based presentations on YouTube nephrology channels.

YouTube is a video-sharing website that is open to the public as a free and easy way to share videos. It has gained so much popularity since it started that is has become a common household name. With that people have easily been able to learn how to navigate through the site to look up videos that spark interest. In the nephrology world not only can lectures and conferences be seen on this but you can see renal ultrasounds and kidney biopsies being done on this site providing another way to learn. YouTube has become like a television for the internet providing "channels" that people can subscribe to. An investigation was done looking at healthcare provider satisfaction with using a Nephrology OnDemand [17] channel. This opinion based study revealed that there was an ability to educate people accurately and efficiently using this vehicle [17]. Some medical schools have created nephro-pathology websites to display pathology slides and explanations that people can access at their convenience as a study aid and adjunctive teaching tool. Sites like this can be used to advance learning at all levels of training [18].

Mobile devices have provided a quick and easy way to access information. A study looked at the website Nephrology On Demand and revealed that of all the visits that the site received $(>15,000), 10 \%$ came from mobile devices. This is a significant number revealing that it may be vital for educational websites to incorporate mobile internet sites as another means of accessing online information [19]. Audio and video streaming via the internet allow people to see presentations or listen to conferences at their own convenience as long as they have an internet source. Most places including your corner coffee shop offer free "Wi-Fi" which is a popular technology that allows electronic devices to exchange data wirelessly using radio waves over a computer network. Podcasts are an example of audio files that can be downloaded or streamed on the internet allowing people to listen to discussions or conferences from any internet source that allows one to hear. An example of this is on ASN's website that provides podcasts regularly regarding international opinions about different topics in nephrology [20]. Videos of lectures and conferences can be downloaded and streamed as well. Free and easy internet visuals through programs like face time or Skype can allow people to see events that are happening live.

\section{FUTURE}

With all of these new modalities for accessing and disseminating information, it is clear that it will change the way nephrology and all fields of medicine are taught. With increased access to this information, a renewed interest in nephrology will follow among the newest crop of future physicians- medical students.

With a greater understanding of the kidney and its function from the start by using shared audio/visual programs including animation accessed through computer programs or online they may be more inclined to be a part of the field in the future. For fellows that have chosen to be a part of the lifelong learning of nephrology, they can start their training in ways that will build a strong foundation. Creating internet modules or PowerPoint presentations that can be shared through programs or institutions through the nation can become a traditional practice. Debates and conferences between fellowship programs can be streamed through the internet to each place. Implementation of new findings can be integrated quicker into practice thereby optimizing patient care the best it can as soon as the newest information is known. Many clinicians are time-poor and may not have had the opportunity to learn about newer technological innovations. New tools such as blogs, social media networks, and audio and video podcasts in Web 2.0 have allowed better exchange of information among physicians across distances. To have the "digital natives" learn nephrology, the training community will have to embrace these new ways of teaching. With the implementation of these different electronic learning avenues from the start of medical education people can easily understand how they can be used to save a clinician's time and energy, while making information management more efficient.

\section{ACKNOWLEDGEMENTS}

Dr. Jhaveri is the blog editor of eAJKD (www.eajkd. org), the official blog of the American Journal of Kidney Diseases.

\section{CONFLICT OF INTEREST}

The authors confirm that this article content has no conflicts of interest. 


\section{REFERENCES}

[1] Prensky M. Digital natives, Digital immigrants. On the Horizon 2001: 9: 5: 2-6.

[2] Howe N, Strauss W. Millennials Rising: the next great generation.

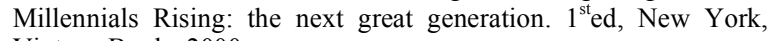
Vintage Books 2000.

[3] Sparks MA, O'Seaghdha CM, Sethi SK, Jhaveri KD. Embracing the Internet as a means of enhancing medical education in nephrology. Am J Kidney Dis 2011; 58: 4: 512-8.

[4] Desai T, Christiano C, Ferris M, Vachharajani T. Nephrology "e" learning made "e"asier. Open Urol Nephrol J 2011; 4: 12-5.

[5] Pashler H, McDaniel M, Rohrer D, Bjork R. Learning styles: concepts and evidence. Psychol Sci Public Interest 2008; 9: 3: 10519.

[6] Nalliah S, Chan SLJ, Ong CLS, Suthan TH, et al. Effectiveness of the use of internet search by third year medical students to establish a clinical diagnosis Singapore. Med J 2010; 51(4): 332.

[7] Falagas M, Ntziora F, Makris C, Malietzis G, Rafailidis P. Google searches help medical students and young doctors reach the correct diagnosis? A pilot study. Eur J Intern Med 2009: 20: 788-90.

[8] Schrier PB, Speigel L, Mattana J, Jhaveri KD. Paging Doctor Google! Google searching as a tool for diagnosing renal disease Annual American Society of Nephrology Kidney Week, Nov 2011; Abstract TH-PO855.

[9] Mena G, Llupià A, García-Basteiro AL, Aldea M, Sequera VG, Trilla A. The willingness of medical students to use facebook as a training channel for professional habits: the case of influenza vaccination. Cyberpsychol Behav Soc Netw 2012; 15: 6: 328-31.
[10] Nair V, Khan S, Jhaveri KD. Interactive journals and the future of Medical Publications. Am J Med (in press).

[11] Twitter Journal Club. Available from: http://www.twitjc.com/ [Accessed June 24, 2012]

[12] eAJKD. Available from: http://www.eajkd.org/ [Accessed June 28, 2012]

[13] CJASN eJournal Club. Available from: http://ejc.cjasn.org/phpBB 3/index.php [Accessed June 23, 2012]

[14] Bahner DP, Adkins E, Patel N, Donley C, Nagel R, Kman NE. How we use social medial to supplement a novel curriculum in medical education. Med Teach 2012; 34: 6: 439-44.

[15] George DR, Dellasega C. Use of social media in graduate level medical humanities education: two pilot studies from Penn State College of Medicine. Med Teach 2011; 33: 8: e429-34.

[16] Desai T, Shariff A, Shariff A, et al. Tweeting the meeting: an indepth analysis of twitter activity at kidney week 2011. PLoS One 2012; 7: e40253.

[17] Desai T, Sanghani V, Fang X, Christiano C, Ferris M. Assessing a nephrology-focused YouTube channel's potential to educate health care providers. J Nephrol 2012; [Epub a head of print].

[18] Desai T, Talento R, Christiano C, Ferris M, Hewan-Lowe K. Webbased nephropathology teaching modules and user satisfaction: the nephrology on -demand experience. Ren Fail 2011; 33: 10: 1046-8.

[19] Desai T, Christiano C, Ferris M. Understanding the mobile internet to develop the next generation of online medical teaching tools. $\mathrm{J}$ Am Med Inform Assoc 2011; 18: 6: 875-8.

[20] American Society of Nephrology Media Center. Available from: http://www.asn-online.org/media/podcasts.aspx [Accessed June 23, 2012] 